\title{
Diversitas Pendidikan Multidimensional Dalam Pertunjukan Kentongan Bambu Laras Banyumas Jawa Tengah
}

\author{
Rifky Fandanu ${ }^{1}$, Wahyu Lestari ${ }^{2}$, Suharto $^{3}$ \\ 1,2,3 Universitas Negeri Semarang, Semarang, Indonesia \\ Email: ${ }^{1}$ fandanurifky44@gmail.com, ${ }^{2}$ wahyupyarlestari@mail.unnes.ac.id
}

\begin{abstract}
This study aims to identify the Kentongan Bambu Laras show and explore the contextualization of educational diversity in the Kentongan Bambu Laras performance. This study uses a qualitative method to recontextualize educational diversity in Kentongan Bambu Laras, Patikraja Village, Patikraja District, Banyumas Regency, Central Java. Data collection techniques include observation, interviews, documentation, and literature study. The data obtained were analyzed with a musicological approach used to analyze the form of Kentongan Bambu Laras performance from how to play and form music and instrumentation organology. The results showed that the value of honesty, discipline value, hard work value, and creative value were found in the Kentongan Bambu Laras performance. Furthermore, the recontextualization of multidimensional education lies in the instrumentation and complexity of the performances to develop physical or motor skills, perceptual, intellectual, emotional, social, creativity.
\end{abstract}

Keywords: multidimensional education diversity, kentongan music performance, Kentongan Bambu Laras

\begin{abstract}
Abstrak: Penelitian ini bertujuan untuk mengidentifikasi pertunjukan Kentongan Bambu Laras dan mengeksplorasi terkait rekontekstualisasi diversitas pendidikan dalam pertunjukan Kentongan Bambu Laras. Pertunjukan Kentongan Bambu Laras merupakan representasi atas wujud kebudayaan dan kesenian yang memiliki diversitas estetik yang berkontribusi dalam pendidikan multidimensional. Penelitian ini menggunakan metode kualitatif terhadap fenomena rekontekstualisasi diversitas pendidikan dalam Kentongan Bambu Laras, Desa Patikraja, Kecamatan Patikraja, Kabupaten Banyumas, Jawa Tengah. Teknik pengumpulan data meliputi observasi, wawancara, dokumentasi, dan studi pustaka. Data yang diperoleh dianalisis dengan pendekatan musikologi yang digunakan untuk menganalisis bentuk pertunjukan kesenian Kentongan Bambu Laras dari cara bermain dan bentuk musik (form), dan organologi (instrumentasi). Hasil penelitian menunjukkan bahwa nilai kejujuran, nilai disiplin, nilai kerja keras, dan nilai kreatif terdapat dalam pertunjukan Kentongan Bambu Laras. Lebih lanjut, rekontekstualisasi pendidikan multidimensional terletak pada instrumentasi dan kompleksitas pertunjukan mengembangkan kemampuan fisik atau motorik, perseptual, intelektual, emosional, sosial, kreativitas.
\end{abstract}

Kata Kunci: Diversitas pendidikan multidimensional, pertunjukan musik kentongan, Kentongan Bambu Laras

Article info:

Received: 04 Mei 2021

Reviewed: 12 Mei 2021

Accepted: 27 Juni 2021

\section{PENDAHULUAN}

Pendidikan secara aksiologi bertujuan untuk mengembangkan potensi manusia ke arah yang positif (Graham, 1997; Van Manen, 1995). Aksiologi diartikan sebagai ilmu yang mempelajari tentang tujuan ilmu pengetahuan atau hakikat dan manfaat yang sebenarnya dari pengetahuan, dan dipahami sebagai teori nilai yang menggunakan penilaian etika dan estetika (Kattsoff, 2004; Van Manen, 1995). Di sisi lain, hal tersebut didukung oleh etika yang berfokus pada perilaku, norma dan adat istiadat manusia di mana estetika membahas tentang nilai keindahan. Oleh karena itu suatu objek yang indah bukan semata-mata bersifat selaras serta berpola baik melainkan harus juga mempunyai kepribadian (Firmadani, 2020, p. 9).

Pendidikan merupakan suatu proses usaha yang dilakukan oleh suatu individu agar dapat mencerdaskan manusia lain dalam bentuk kebiasaan melakukan perintah Tuhan, menumbuhkan kepekaan sosial, menumbuhkan rasa tanggung jawab, peduli, amanah, dan memiliki kepribadian yang mulia (Shields, 
2015). Karakter adalah kualitas mental, moral, akhlak seseorang yang dibentuk sehingga menghasilkan kepribadian atau watak yang menjadi ciri khas orang tersebut (Rivers, 2016; Shields, 2015). Pendidikan karakter berkelindan dengan keseharian dalam wujud kebudayaan dan kesenian yang memiliki diversitas estetik. Namun, pendidikan karakter dalam keseharian kadang dimaknai secara komplementer. Diversitas estetik yang di dalamnya terdapat pendidikan karakter jarang tereksplorasi dalam bentuk kajian, pengembangan, dan implikasi di kurikulum pendidikan. Salah satu bentuk seni yang bersifat populer dalam masyarakat urban adalah pertunjukan Kentongan.

Pertunjukan Kentongan merupakan suatu pertunjukan kesenian daerah yang terdiri dari alat musik perkusi dan melodis (Sasongko, 2017, p. 67). Pertunjukan Kentongan di dalamnya terdapat Kentong yang merupakan alat musik dari bambu yang dimainkan dengan cara dipukul. Seiring perubahan zaman, Kentong berkembang terus dari awal bentuknya hingga saat ini. Mulai dari Kentong Tek-tek, lalu berubah bentuk menjadi Kentong Geyong, dan saat ini menjadi Kentong Racak. Alat pemukul Kentong terbuat dari bambu atau batang kayu jati yang dipahat. Pada zaman dahulu, Kentong digunakan oleh masyarakat sebagai tanda ketika ada bencana, sebagai media komunikasi jarak jauh antar masyarakat, penanda adzan, dan penanda bahaya (Aryani, 2010, p. 45). Di dalam pertunjukan Kentongan, instrumen yang dimainkan terdiri dari Kentong, ropel, bass, gambang, cello, angklung, dan cymbal (wawancara: Sujiyono, 2021).

Pertunjukan Kentongan sebagai salah satu kekayaan kesenian yang dimiliki Indonesia membuat ia hadir tidak hanya sebagai proses hibriditas budaya dari generasi-generasi sebelumnya (Bhabha, 1994). Eksistensinya diakui hingga saat ini karena keindahan yang terwujud dari teknik permainan dan hasil bunyinya yang kompleks namun padu (Lo, 2015). Lebih lanjut, pertunjukan Kentongan sebagai sebuah diversitas budaya di dalamnya terdapat poin-poin yang harus dieksplorasi. Hal tersebut dikarenakan pertunjukan Kentongan bernegosiasi antara musik populer masyarakat urban dan musik kontemporer. Pertunjukan Kentongan sebagai musik kontemporer di Indonesia mulai dirasakan sejak digelarnya acara Pekan Komponis Muda tahun 1979 di Taman Ismail Marzuki Jakarta. Melalui acara tersebut, komunikasi para seniman antar daerah dengan berbagai macam latar belakang budaya dan instrumen musiknya lebih terjalin.

Forum diskusi dan dialog antar seniman dalam acara tersebut saling memberikan kontribusi sehingga membuka paradigma kreatif pertunjukan musik menjadi lebih luas (Adom, 2019). Namun, eksplorasi terkait pertunjukan Kentongan perlu diwacanakan terutama dalam kaitannya dengan pemanfaatan unsur alam sebagai sebuah diversitas estetik yang dimiliki. Diversitas estetik memberikan dampak pada pendidikan, di mana dalam pertunjukan Kentongan memberikan kompleksitas yang bersifat interaktif antara estetik dan pendidikan (Georgii-Hemming et al., 2020; Thibeault, 2020). Tak hanya itu, unsur-unsur di dalamnya mengandung banyak ilmu pengetahuan serta nilai-nilai kehidupan yang luhur. Kuatnya keberadaan pertunjukan Kentongan saat ini membuatnya terintegrasi dan akhirnya berelasi dengan berbagai hal dalam kehidupan (Tuchman-Rosta, 2014). Unsur-unsur di dalam pertunjukan Kentongan dipercaya dapat memengaruhi pikiran dan perasaan seseorang.

Salah satu grup pertunjukan musik Kentongan yang mengakomodasi hibriditas budaya dan diversitas di dalamnya adalah grup musik Kentongan Bambu Laras; merupakan sebuah grup musik yang beralamat di RT.01 RW.07 Desa Patikraja, Kecamatan Patikraja, Kabupaten Banyumas, Jawa Tengah, yang saat ini sudah memasuki ke generasi ke-4 sejak berdirinya pada 1997 yang dikelola oleh Sujiyono. Pada Kentongan Bambu Laras ini alat musik yang dominan dimainkan adalah Kentong berjumlah 20; 2 buah angklung sebagai alat musik melodis dan harmonis; 1 buah ropel atau ketak sebagai alat musik ritmis; 1 buah cello sebagai alat musik ritmis; 1 bass; 1 buah gambang sebagai pelengkap; dan 2 buah suling sebagai pelengkap. Semua alat musik yang digunakan pada grup Kentongan Bambu Laras adalah alat musik tradisional yang ada di Kabupaten Banyumas (wawancara: Sujiyono, 2021).

Penelitian terkait rekontekstualisasi diversitas pendidikan dalam pertunjukan Kentongan Bambu Laras masih jarang dilakukan. Hal tersebut didasari atas pencarian tinjauan literatur yang dilakukan secara sistematis (Denzin \& Lincoln, 2013) terhadap pangkalan data artikel baik skala nasional 
maupun internasional yaitu GoogleScholar, neliti.com, ScienceDirect, Taylor \& Francis Online, dan JSTOR.

Literatur tentang rekontekstualisasi diversitas pendidikan dalam pertunjukan musik berbasis grup sering dikaitkan dengan perubahan sosial dan pendidikan, yang berpendapat bahwa transformasi sosial adalah pendorong dan tercermin dalam perubahan estetika dan pendidikan (Koops, 2017; Mishra et al., 2011; Thibeault, 2020). Hal tersebut didukung dengan argumentasi yang mengatakan bahwa masyarakat selalu berubah dan percaya bahwa pendidikan adalah jawaban yang menjanjikan untuk masalah dan tantangan dalam masyarakat, dan medium yang tepat adalah seni musik (Allen, 2008; Nurseto et al., 2015; Stevens, 2018; Thibeault, 2020). Bentuk seni yang selalu berubah dapat mengamati jejak progresivisme dalam dukungannya terhadap gagasan bahwa diversitas pendidikan terus berubah dan menghasilkan, mencerminkan, dan memandu perubahan sosial yang diawali dengan estetika (Mantie, 2013; Thibeault, 2020; Wiggins, 2015). Oleh karena itu, pertunjukan musik berbasis grup adalah fitur pendidikan yang tidak dapat disangkal karena pendidikan dalam fungsi sosial melibatkan mekanisme untuk mengirimkan pengetahuan dan norma serta nilai masyarakat sebagai sarana yang digunakan masyarakat untuk mempersiapkan keberadaannya sendiri (Dewey, 1980; Fott, 2009; Koopman, 2005).

Instrumen musik dapat menjadi identitas kultural dan sebagai aset pariwisata (Conway et al., 2010; Woody et al., 2019). Ketika dilakukan konteks pada penelitian tentang rekontekstualisasi diversitas pendidikan dalam pertunjukan kentongan, maka identitas musik kentongan Bambu Laras membentuk suatu pola tertentu atau kebiasaan yang mendefinisikan grup tersebut (Adams, 2006; Hall, 2002; Soewarlan, 2019). Budaya sendiri dapat di definisikan sebagai cara hidup atau berkembang yang dimiliki oleh sekelompok orang dan diwariskan generasi ke generasi (Noland, 2009). Sehingga identitas budaya memiliki pengertian suatu ciri khas khusus atau karakter khusus yang melekat dalam suatu kebudayaan sehingga bisa dibedakan dari kebudayaan yang lain. Oleh karenanya, Kentongan Bambu Laras memiliki potensi menjadi salah satu aset budaya yang di dalam pertunjukannya terdapat poin-poin pendidikan.
Dari perbandingan atas penelitian yang pernah dilakukan dapat menjadi pijakan dalam memetakan penelitian sekaligus menunjukkan kurangnya penelitian tentang diversitas pendidikan dalam pertunjukan kentongan. Sebagian besar penelitian yang memiliki relevansi lebih membahas soal aspek instrumentasi dan kajian musik, namun tidak membahas hal-hal yang ada di sekitar konteks penelitian yaitu musik. Oleh karenanya, penelitian tentang rekontekstualisasi diversitas pendidikan dalam pertunjukan Kentongan Bambu Laras belum pernah dilakukan sehingga memiliki tingkat orisinalitas dan kebaruan.

Kuatnya pengaruh unsur dalam pertunjukan Kentongan pada akhirnya dimanfaatkan oleh dunia pendidikan. Hal ini tentunya sesuai dengan tujuan pendidikan yakni membawa manusia untuk hidup lebih baik (Kearns, 2019; Ki Hadjar Dewantara, 2004). Manusia sejak lahir bagaikan kain putih polos yang tidak membawa corak apa pun ke dalam dunia. Untuk melengkapi dan memperindah, manusia membutuhkan pendidikan. Dimulai dari keluarga dan juga ke dalam lembagalembaga formal. Pertunjukan Kentongan dianggap efektif dalam penggunaannya sebagai media pendidikan khususnya dalam lingkup pendidikan multidimensional. Oleh karena itu, penelitian ini bertujuan untuk mengidentifikasi pertunjukan Kentongan Bambu Laras dan mengeksplorasi terkait rekontekstualisasi diversitas pendidikan dalam pertunjukan Kentongan Bambu Laras. Hal tersebut dikarenakan selain pertunjukan Kentongan Bambu Laras menjadi wujud representasi kebudayaan dan kesenian yang memiliki diversitas estetik, mereka juga menampilkan pendidikan multidimensional di dalamnya; berbeda dengan pertunjukan kentongan lainnya yang tidak mengakomodasi aspek multi yang terintegrasi dengan disiplin lain.

\section{METODE}

Penelitian ini menggunakan metode kualitatif terhadap fenomena rekontekstualisasi diversitas pendidikan dalam Kentongan Bambu Laras (Lune \& Berg, 2017; Tashakkori \& Creswell, 2008). Sumber data dalam penelitian ini adalah Kentongan Bambu Laras dan Sujiyono selaku pengelola Kentongan Bambu Laras, yang berlokasi di RT.01 RW.07 Desa Patikraja, Kecamatan Patikraja, Kabupaten Banyumas, Jawa Tengah.

Pengumpulan data pada penelitian ini lakukan dengan cara observasi, wawancara atas 
materi audio-visual terkait Kentongan Bambu Laras yang akan juga dipadukan dengan studi pustaka (Shkedi, 2019; Tashakkori \& Creswell, 2008). Observasi dilakukan untuk mengamati perilaku dan aktivitas Kelompok Bambu Laras. Data dari observasi didukung oleh data wawancara yang dilakukan secara semi terstruktur dengan mengajukan pertanyaan terbuka terhadap Sujiyono selaku pengelola atau koordinator Kentongan Bambu Laras.

Setelah data terkumpul, langkah pertama dimulai dengan mengolah dan mempersiapkan data untuk dianalisis yang melibatkan transkripsi wawancara, scanning materi, mengetik data lapangan, ataupun memilah dan menyusun data yang didapat ke jenis-jenis yang berbeda sesuai informasi (Miles et al., 2018; Tashakkori \& Creswell, 2008). Dalam rencana penelitian ini, data yang ditranskrip tidak hanya berupa hasil wawancara saja namun juga video atau rekaman ketika proses latihan dan pertunjukan kelompok Kentongan Bambu Laras. Langkah kedua adalah membaca keseluruhan data dan membangun pemikiran umum atas informasi yang diperoleh. Langkah ketiga ialah memulai coding data untuk mengorganisasikan data dengan pengumpulan potongan data baik berupa teks atau gambar dan menuliskan kategori dalam batasan tertentu (Tashakkori \& Creswell, 2008). Selanjutnya, data dianalisis dengan pendekatan musikologi yang digunakan untuk menganalisis bentuk pertunjukan kesenian Kentongan Bambu Laras yang dijadikan sebagai objek penelitian. Musikologi secara sederhana dijelaskan sebagai ilmu yang mempelajari tentang sejarah, teori dan analisa. Analisa dalam musikologi dibagi menjadi teknik yang terdiri dari cara bermain dan bentuk musik (form), dan organologi (instrumentasi) (Banoe, 2003; Dubowsky, 2016; Lundström, 2018; Prier, 1989). Dari hal tersebut melihat seni kentongan sebagai kesenian tradisional yang memiliki unsur-unsur musik di dalamnya. Unsur-unsur tersebut terdiri dari melodis yang ada dalam alat musik angklung melodis; unsur ritmis yang ada dalam alat musik kentong, cello, ropel, bass; dan harmonis yang ada dalam alat musik angklung.

\section{HASIL DAN PEMBAHASAN}

Penggunaan musik tradisional memiliki historiografi yang identik dengan pengajaran luar sekolah yang bersifat non-formal (Bakka \& Karoblis, 2017; Boyle-Baise et al., 2008). Kalangan pendidik yang melihat potensi seni musik tradisional sebagai salah satu media yang dapat digunakan dalam proses pendidikan di sekolah, khususnya sekolah-sekolah nonkesenian, mencoba untuk memasukkan seni musik tradisional dalam kurikulum. Musik tradisional selain sebagai media untuk melestarikan kemudian mengenalkan ragam warisan budaya nusantara dan menumbuhkan rasa kepemilikan, banyak makna yang terkandung dari proses-proses pelatihan memainkan musik tradisional itu sendiri (Cannon, 2016; Muzaffar \& Otero-Pailos, 2015). Oleh karena itu, melalui musik tradisional baik dari pertunjukan atau kemampuan instrumentasinya, anak-anak diharapkan memiliki kemampuan untuk menguasai olah vokal, memainkan alat musik sederhana, mengapresiasi karya musik serta berketrampilan yang mencakup segala aspek kecakapan hidup (life skills) yang meliputi ketrampilan personal, vokasional, dan akademik (Ho, 2014; Pitts, 2017).

Berkaitan dengan pengajaran luar sekolah dan pendidikan seni musik, pertunjukan musik kentongan merupakan sebuah pertunjukan yang sangat banyak dinantikan oleh masyarakat Kabupaten Banyumas. Terbuki jika ada event ulang tahun Kabupaten Banyumas, pertunjukan tersebut terus dilombakan dan banyak yang menjadi peserta untuk mengikutinya. Hal tersebut menjadi salah satu pijakan diversitas pendidikan yang tercipta dari transformasi estetik ke pendidikan (Thibeault, 2020; Weiss, 2010). Selain itu, penonton yang melihatnya selalu ramai. Grup musik Kentongan Bambu Laras yang sudah berdiri sejak tahun 1997 selalu menjadi jawara dari perhelatan yang digelar oleh pemerintah daerah mulai dari tingkat Kabupaten Banyumas hingga tingkat Provinsi Jawa Tengah. Mereka memiliki pesona yang di dalamnya terdapat berbagai macam aspek, di mana menjadi representasi diversitas Kentongan Bambu Laras.

Dari pertunjukannya, alat musik yang dimainkan dalam pertunjukan tersebut terdiri dari Kentong berjumlah 20; 2 buah angklung sebagai alat musik melodis dan harmonis; 1 buah ropel atau ketak sebagai alat musik ritmis; 1 buah cello sebagai alat musik ritmis; 1 bass; 1 buah gambang sebagai pelengkap; dan 2 buah suling sebagai pelengkap. Seiring perkembangan zaman alat musik kentongan terus berkembang mulai dari kentong tek-tek, 
kentong geyong, dan kentong racak. Namun saat ini banyak grup yang menggunakan kentong racak. Sujiyono menyatakan hal tersebut dikarenakan alat musik kentongan sangat representatif untuk digunakan. Sebab dalam pertunjukan kentongan para pemain tidak hanya harus bisa bernyanyi, dan bermain alat musik. Namun para pemain harus bisa bernyanyi, sembari bermain alat musik dan melakukan koreografi.

Kompleksitas alat musik kentong rancak memperkaya diversitas pendidikan yang kali ini terkait dengan bentuk dan bahan yang digunakan, di mana kentong rancak terbuat dari bambu dan dimainkan dengan cara dipukul. Alat musik tersebut merupakan alat musik ritmis yang bernada. Di mana terdapat dua buah nada yaitu nada 1 (do) dan 3 ( $\mathrm{mi}$ ) yang biasa dimainkan dengan ketukan 2 atau ketukan 4 (wawancara: Sujiyono, 2021). Selain kentong juga ada alat musik ropel yang berfungsi sebagai alat musik ritmis. ropel dan cello harus dapat menyatu atau saling melengkapi. Hal tersebut menurut Sujiyono, kedua alat musik tersebut merupakan sebuah satu kesatuan yang tidak bisa dipisahkan. Kedua alat musik tersebut harus selaras agar terdengar harmonis. Alat musik berikutnya yang digunakan adalah alat musik melodis dan harmonis yaitu angklung. Dalam hal ini alat musik tersebut merupakan alat musik inti yang harus ada dalam permainan musik kentongan. Fungsi dari alat musik angklung yaitu membawakan melodi dan harmonisasi dari semua lagu yang akan dibawakan. Alat musik terakhir yang harus ada dalam permainan musik kentongan adalah bass. Bass berperan untuk memainkan nada rendah. Alat musik tersebut terbuat dari drum plastik yang sudah tidak terpakai. Lalu ditutup dengan karet bekas ban truk. Alat tersebut dimainkan dengan cara dipukul. Stik pemukul terbuat dari kayu lalu dibalut dengan karet.

Di setiap pertunjukan Kentongan Bambu Laras, menurut Sujiyono jumlah pemain disesuaikan dengan besarnya acara yang diselenggarakan dan lokasi pementasan. Jika acara besar dan lokasi pementasan luas maka jumlah pemain bisa mencapai 40 orang. Namun jika acara kecil dan lokasi pementasan kecil maka jumlah pemain hanya 20 orang. Dari hasil wawancara diperoleh hasil bahwa untuk mendirikan dan tetap menjaga kesenian tersebut tetap berprestasi dan eksis sangat penting sekali adanya nilai-nilai pendidikan karakter yang harus diajarkan kepada para pemain kentongan bambu laras diantaranya yaitu nilai kejujuran, nilai disiplin, nilai kerja keras, dan nilai kreatif (Bonnett, 2017; Rivers, 2016). Kejujuran dapat dilihat dari transparansi antara pengurus dan para pemain mengenai pemasukan dan pengeluaran yang tercatat dengan rapi dan terbuka untuk diketahui oleh seluruh anggota yang saat ini sudah sampai pada generasi ke-4 penerus kentongan grup bambu laras. Nilai disiplin dapat diperoleh dari kedisiplinan ketika mereka berlatih untuk persiapan mengikuti perlombaan. Terbukti dari kedisiplinan yang baik grup musik bambu laras berhasil memperoleh 2 kali Piala Presiden dalam pentas yang diselenggarakan. Selain itu, menjadi grup kentongan terbaik yang tiap tahunnya di Kabupaten Banyumas. Menurut Sujiono untuk mencapai titik prestasi tertinggi sangat dibutuhkan kerja keras yang serius yang harus dimiliki oleh para pemain. Terbukti ketika tahun 2003 mereka hanya menjadi juara 2 di tingkat Kecamatan Patikraja. Namun, dengan kerja keras bersama seluruh pemain, pada tahun 2004 mereka menjadi juara di tingkat Kabupaten hingga tingkat Provinsi. Di mana menurut Sujiyono tahun 2004 adalah titik balik bangkitnya grup Kentongan Bambu Laras. Semenjak saat itu grup ini menjadi jawara dan dikenal oleh seluruh lapisan masyarakat Kabupaten Banyumas. Nilai kreatif pun mulai muncul dari aransemen-aransemen yang berbeda jauh dari lagu asli yang dibawakan namun tetap mempertahankan lagu asli dan mempertahankan tradisional atau jika menurut narasumber grup Kentongan Bambu Laras merupakan grup kentongan klasik (Cannon, 2016; Johansson, 2012), karena selalu mempertahankan nilai-nilai tradisi dan tetap mengajarkan nilai-nilai pendidikan karakter pada setiap anggota grup Kentongan Bambu Laras.

Di dalam pertunjukan musik berbasis grup, terdapat interaksi musikal dan sosial di antara rekan penampil (Goodman, 2002). Menurutnya ada empat aspek yang penting untuk diperhatikan dalam pertunjukan musik berbasis grup yaitu coordination (koordinasi), communication (komunikasi), the role of individu (peran individu), dan social factors (faktor sosial) (Dubowsky, 2016; Goodman, 2002). Koordinasi harus tercipta dengan baik antar individu terutama dalam perihal menjaga tempo, dan menjaga kekompakan ketika adanya perubahan-perubahan pada dinamik maupun tempo. Peran individu ini dimaksudkan bahwa 
setiap pemain memiliki peran sesuai pada karakternya masing-masing namun ketika bermain pertunjukan musik berbasis grup, tiap pemain tetap harus menyatu dengan rekannya. Hal tersebut sudah terepresentasikan dalam pertunjukan Kentongan Bambu Laras. Di dalam pertunjukan Kentongan Bambu Laras juga terdapat interaksi antar pemain, dan adanya demokrasi serta peran seorang pemimpin dalam kelompok. Hal ini menjelaskan bahwa dalam pertunjukan musik berbasis grup diperlukan aspek dalam keterampilan bermusik berbasis grup secara non-musikal (Goodman, 2002), dan tidak terbatas pada keterampilan mandiri, namun adanya interaksi antar rekan penampil. Hal tersebut untuk menghindari superioritas salah satu anggota, karena masing-masing anggota memiliki peran yang penting serta tanggung jawab (Bonneville-Roussy et al., 2020; Johansson, 2012).

Diversitas pendidikan dalam Kentongan Bambu Laras terwujud dalam implementasinya sebagai media pendidikan multidimensional. Seni yang multidimensional pada dasarnya dapat mengembangkan kemampuan dasar manusia seperti fisik, perseptual, intelektual, emosional, sosial, kreativitas, dan estetik (M. B. T. Sampurno et al., 2020; T. Sampurno, 2015). Berdasarkan pernyataan tersebut, maka dapat dilihat bahwa Kentongan Bambu Laras memiliki potensi untuk mengembangkan pikiran, perasaan, dan tingkah laku manusia. Kentongan Bambu Laras yang memiliki berbagai unsur yang kompleks mampu berperan dalam pendekatan pendidikan tersebut.

Jika dikupas berdasarkan masing-masing unsur pendekatan multidimensional, maka dapat dikorelasikan dengan peran unsur-unsur dalam Kentongan Bambu Laras. Pertama, mengenai kemampuan fisik anggotanya. Keterampilan fisik atau bisa disebut motorik dapat diolah melalui Kentongan Bambu Laras. Untuk pengembangan kemampuan dasar dari kemampuan fisik atau motoriknya dengan memperkenalkan dan melatih gerakan motorik kasar dan halus, meningkatkan kemampuan mengelola, mengontrol gerakan tubuh dan koordinasi (Folkestad, 2005; Iryanti et al., 2021; Lestari \& Barus, 2021). Jika dikaitkan dengan peran Kentongan Bambu Laras bagi pengembangan keterampilan fisik anak, maka akan berkorelasi. Unsur-unsur gerak fisik dalam Kentongan Bambu Laras seperti memukul serta olah vokal di dalamnya juga menjadi penunjang pelatihan gerak motorik halus. Jika dikontekstualisasikan pada anak-anak, bisa juga sebagai pelatihan gerak motorik kasar juga kontrol dan pengelolaan gerak (Boyd, 2013; Willis, 2007). Dalam bermain instrumen musik, sebagai media Kentongan Bambu Laras, maka tidak diperbolehkan untuk semaunya sendiri. Adanya aturan permainan di setiap instrumen untuk mewujudkan hasil bunyi yang padu, dibutuhkan kerja sama para pemain sesuai dengan porsinya masing-masing.

Perkembangan perseptual menjadi unsur pendidikan multidimensional yang selanjutnya. Perkembangan perseptual merupakan proses pengenalan individu terhadap lingkungan melalui gayanya dan menangkap maknanya dengan sensori panca indera mereka yang kemudian itu dicerna di dalam otak mereka (Noble \& McAdams, 2020). Perkembangan perseptual merupakan reaksi dari rangsangan alat inderanya yang baik melalui penglihatan, pendengaran, perabaan, dan yang kemudian itu diolah di dalam otak menjadi suatu persepsi yang belum diketahui kebenarannya (Koops, 2017; Lin, 2019; Noble \& McAdams, 2020). Di dalam perkembangan ini terdapat tiga proses, yakni sensasi, persepsi, dan atensi (Noble \& McAdams, 2020). Sensasi yakni sebuah peristiwa penerimaan informasi yang diterima melalui berbagai macam indera yang terjadi karena adanya kontak indera dengan penerima. Contohnya, saat seorang pemain Kentongan Bambu menunjukkan kemampuannya dengan maksimal untuk mencari perhatian guru atau penontonnya. Persepsi merupakan sebuah interaksi terhadap sebuah informasi yang ditangkap oleh indera penerima dalam sebuah keterampilan yang dapat memberikan dampak langsung pada perseptual (Noble \& McAdams, 2020). Contohnya, saat diajari untuk bermain kentong, pada awalnya ia memukul dengan keras dengan sesuka hatinya. Ini merupakan bentuk perseptual bahwa ada benda berbunyi teratur yang harmonis untuk dimainkan dengan keras. Ketiga, yakni atensi yang mengacu pada selektivitas persepsi, akan tetapi lebih cenderung pada kesadaran, hanya tertuju pada satu objek dan objek lainnya tidak direspons (Noble \& McAdams, 2020). Contohnya saat anak diajari untuk bermain Kentongan Bambu Laras sesuai konvensinya, maka ia hanya fokus pada permainannya dan mengabaikan hal-hal termasuk orang-orang di sekelilingnya. Hal ini 
dikarenakan ia fokus pada permainannya sambil menyesuaikan dengan konvensi yang ada.

Selanjutnya yakni perkembangan intelektual atau dapat disebut perkembangan kognitif dalam Kentongan Bambu Laras. Perkembangan ini berasal dari tekanan biologi untuk menyesuaikan diri dengan lingkungannya (melalui dua proses asimilasi dan akomodasi) dan adanya pengorganisasian struktur berpikir (Lin, 2019; Rutter \& Garmezy, 1983). Di dalam pertunjukan Kentongan Bambu Laras beberapa anggota pada dasarnya belum sepenuhnya menyadari apa yang mereka lakukan. Mereka hanya senang karena dapat berekspresi dan bergerak dan pengalaman tersebut akan membentuk intelektual mereka. Pada akhirnya, pengalaman bermain Kentongan Bambu Laras yang dilakukan secara konsisten dan dalam jangka panjang akan membentuk pola pikir yang terorganisir karena konvensi-konvensi yang ketat (Adolph \& Berger, 2015; Bahatmaka $\&$ Lestari, 2012; Chen, 2014).

Perkembangan selanjutnya yakni perkembangan emosi yang merupakan pengalaman afektif yang disertai penyesuaian dari dalam diri individu tentang keadaan mental dan fisik yang berwujud suatu tingkah laku yang tampak (Holt et al., 2013; Patelli, 2017). Pertunjukan Kentongan Bambu Laras akan menunjang perkembangan emosi supaya lebih tertata dan matang. Metode belajar dalam Kentongan Bambu Laras yang menunjang perkembangan emosi antara lain belajar dengan coba-coba, meniru, mempersamakan diri, pengkondisian, serta belajar di bawah bimbingan dan pengawasan dan itu semua ada di dalam pertunjukan Kentongan Bambu Laras (Mignonneau \& Sommerer, 2005). Unsur-unsur dalam Kentongan Bambu Laras dirasa mampu menunjang proses perkembangan emosional. Misalnya saat ingin memukul instrumen dilakukan dengan coba-coba, menirukan cara bermain kentongan sama seperti yang dicontohkan oleh kelompok lainnya, pengkondisian dari yang tidak suka menjadi suka, serta belajar menggunakan kentong di bawah bimbingan dan pengawasan akan mengontrol dan membentuk emosional yang lebih teratur dan matang. Selain hal-hal terkait teknik permainan, usaha-usaha untuk menghasilkan produksi bunyi yang diharapkan juga mampu membentuk perkembangan emosional mereka. Perkembangan emosional ini pada akhirnya memiliki karakter karena emosionalnya lebih matang dan tertata.
Tumbuhnya pribadi individu tidak hanya dinilai dari kecerdasan intelektual namun juga berkarakter (Bates, 2019; Putriningtyas et al., 2015). Dengan memiliki karakter yang kuat, maka individu akan mampu bertahan hidup dalam lingkungan yang lebih luas dan kompleks.

Perkembangan sosial juga tak kalah penting dalam pendidikan multidimensional. Tingkah laku pembangkangan yakni berusaha melawan sebagai reaksi terhadap penerapan disiplin atau tuntutan lingkungan yang tidak sesuai dengan kehendak individu. Tingkah laku tersebut dapat dikontrol oleh Kentongan Bambu Laras. Porsi-porsi permainan tiap instrumen yang berbeda-beda dapat meminimalisir tingkah laku pembangkangan supaya tidak berdampak negatif (Conway et al., 2010; Johansson, 2012). Begitu pula dengan tingkah laku yang lain, di mana perkembangan sosial yang matang akan memudahkan individu dalam bertahan hidup di lingkungan, di mana akan mampu beradaptasi dengan norma-norma sosial juga interaksi sosial di lingkungan hidupnya.

Selanjutnya yakni pengembangan kreativitas. Kreativitas adalah kemampuan untuk memikirkan mengenai sesuatu dengan cara baru yang tidak biasa dan menampilkan cara pemecahan masalah yang unik (James \& Sternberg, 2010). Sternberg memperkenalkan kreativitas dalam teori mengenai kecerdasan, mengatakan bahwa banyak individu yang kecerdasannya tinggi yang menghasilkan karyakarya besar tetapi tidak selalu karya-karya baru (2010). Orang-orang yang kreatif cenderung berpikir divergen (Hernández-Torrano \& Ibrayeva, 2020; James \& Sternberg, 2010), dan hal tersebut terepresentasikan dari pertunjukan Kentongan Bambu Laras. Kreativitas dapat dirangsang dengan penyediaan instrumen sebagai media ekspresi yang dalam pertunjukannya bersifat luwes dan banyak peluang untuk memodifikasi permainan sehingga mampu merangsang ide-ide baru untuk saling menghasilkan produk bunyi yang dinamis namun tetap harmonis. Instrumeninstrumen dalam Kentongan Bambu Laras menentukan dinamisasi garap sehingga memiliki peluang yang tinggi untuk menuntut kreativitas pemainnya. Tak hanya itu, permainan volume suara keras dan pelan serta pergantian tempo lambat, sedang, dan cepat secara dinamis juga mampu mengembangkan kreativitas. Unsur kreativitas ini memiliki kedudukan paling tinggi dalam menunjang 
pendidikan multidimensional oleh Kentongan Bambu Laras.

\section{KESIMPULAN}

Pertunjukan musik Kentongan Bambu Laras terdiri dari kentong berjumlah 20; 2 buah Angklung sebagai alat musik melodis dan harmonis; 1 buah ropel atau ketak sebagai alat musik ritmis; 1 buah cello sebagai alat musik ritmis; 1 bass; 1 buah gambang sebagai pelengkap; dan 2 buah suling sebagai pelengkap. Selain itu, para pemain harus dapat memainkan alat musik kentongan sambil bernyanyi dan melakukan koreografi. Sehingga, mereka harus benar-benar pintar agar dapat menerima materi yang diajarkan dan bermain dengan baik. Hasil penelitian menunjukkan bahwa nilai kejujuran, nilai disiplin, nilai kerja keras, dan nilai kreatif terdapat dalam pertunjukan Kentongan Bambu Laras. Lebih lanjut, rekontekstualisasi pendidikan multidimensional terletak pada instrumentasi dan kompleksitas pertunjukan mengembangkan kemampuan fisik atau motorik, perseptual, intelektual, emosional, sosial, kreativitas.

Penelitian ini memiliki limitasi, yaitu pada cakupan spasial penelitian yang berada dalam lingkup Kentongan Bambu Laras, Kabupaten Banyumas. Hal tersebut menyebabkan singularitas dalam varietas bentuk pertunjukan musik kentongan. Oleh karenanya, perlu dilakukan penelitian terkait dalam cakupan spasial yang lebih variatif seperti Yogyakarta, Semarang, atau Surakarta. Selain itu, terdapat saran dari peneliti terkait pemerintah daerah, di mana dapat menjadi fasilitator melalui Dinas Kebudayaan dan Pariwisata agar dapat terus menyelenggarakan event yang melibatkan grup kentongan yang ada di Kabupaten Banyumas sebagai upaya melestarikan kesenian tradisional khususnya kesenian kentongan di Kabupaten Banyumas.

\section{DAFTAR PUSTAKA}

Adams, K. M. (2006). Art as Politics: ReCrafting Identities, Tourism, and Power in Tana Toraja, Indonesia. University of Hawai'i Press. https://doi.org/10.1017/cbo978113903382 4.002

Adolph, K. E., \& Berger, S. E. (2015). Physical and Motor Development. In M. $\mathrm{H}$. Bornstein \& M. E. Lamb (Eds.), Developmental Science: An Advanced Textbook (7th ed., pp. 261-333). Psychology Press/Taylor \& Francis.
Adom, D. (2019). The place and voice of local people, culture, and traditions: A catalyst for ecotourism development in rural communities in Ghana. Scientific African, 6.

https://doi.org/10.1016/j.sciaf.2019.e0018 4

Allen, R. (2008). The Anthropology of Art and the Art of Anthropology - a Complex relationship (Issue March). University of Stellenbosch.

Aryani, I. K. (2010). Pembelajaran Abad 21: Kembali Berguru pada 'Filosofi Kentongan' Sebagai Pelestarian Budaya Banyumas. 8719(2006), 43-49.

Bahatmaka, A., \& Lestari, W. (2012). Fungsi Musik Dalam Kesenian Kuntulan Kuda Kembar Di Desa Sabarwangi Kecamatan Kajen Kabupaten Pekalongan Sebagai Sarana Integrasi Sosial. Catharsis: Journal of Arts Education, 1(2).

Bakka, E., \& Karoblis, G. (2017). Writing "A Dance": Epistemology for Dance Research. Yearbook for Traditional Music, 42, 167-193.

Banoe, P. (2003). Kamus Musik. Kanisius.

Bates, A. (2019). Character education and the 'priority of recognition.' Cambridge Journal of Education, 49(6), 695-710. https://doi.org/10.1080/0305764X.2019.1 590529

Bhabha, H. K. (1994). The Location of Culture. Routledge.

Bonnett, M. (2017). Environmental Consciousness, Sustainability, and the Character of Philosophy of Education. Studies in Philosophy and Education, 36(3), 333-347. https://doi.org/10.1007/s11217-016-9556$\mathrm{x}$

Bonneville-Roussy, A., Hruska, E., \& Trower, H. (2020). Teaching Music to Support Students: How Autonomy-Supportive Music Teachers Increase Students' WellBeing. Journal of Research in Music Education, 68(1), 97-119. https://doi.org/10.1177/002242941989761 1

Boyd, M. (2013). "I love my work but..." The professionalization of early childhood education. Qualitative Report, 18(36), 120.

Boyle-Baise, M., Hsu, M. C., Johnson, S., Serriere, S. C., \& Stewart, D. (2008). 
Putting reading first: Teaching social studies in elementary classrooms. Theory and Research in Social Education, 36(3), 233-255.

https://doi.org/10.1080/00933104.2008.10 473374

Cannon, A. M. (2016). Tradition, still remains: sustainability through ruin in Vietnamese music for diversion. Ethnomusicology Forum, 25(2), 146-171. https://doi.org/10.1080/17411912.2016.11 75313

Chen, W. (2014). Psychological needs satisfaction, motivational regulations and physical activity intention among elementary school students. Educational Psychology, 34(4), 495-511. https://doi.org/10.1080/01443410.2013.82 2959

Conway, C., Eros, J., Pellegrino, K., \& West, C. (2010). Instrumental music education students' perceptions of tensions experienced during their undergraduate degree. Journal of Research in Music Education, 58(3), 260-275.

Denzin, N. K., \& Lincoln, Y. S. (Eds.). (2013). Collecting and Interpreting Qualitative Materials (4th ed.). SAGE Publications.

Dewey, J. (1980). Art as Experience. Perigee Books.

Dubowsky, J. C. (2016). Intersecting Film, Music, and Queerness. Palgrave Studies in Audio-Visual Culture Series. https://doi.org/10.1057/9781137454218

Firmadani, F. (2020). Konsep Dasar Pendidikan Berkarakter. 1-15.

Folkestad, G. (2005). Here, there and everywhere: music education research in a globalised world. Music Education Research, 7(3), 279-287. https://doi.org/10.1080/146138005003243 90

Fott, D. (2009). John Dewey and the Mutual Influence of Democracy and Education. The Review of Politics, 71(Political Philosophy in the Twentieth Century), 719.

Georgii-Hemming, E., Johansson, K., \& Moberg, N. (2020). Reflection in higher music education: what, why, wherefore? Music Education Research, 22(3), 245256.

https://doi.org/10.1080/14613808.2020.17 66006

Goodman, E. (2002). Ensemble performance. In
J. Rink (Ed.), Musical Performance: A Guide to Understanding (pp. 153-167). Cambridge University Press. https://doi.org/10.1017/CBO97805118117 39.012

Graham, G. (1997). Philosophy of the Art. Routledge.

Hall, S. (2002). Representations: Cultural Representations and Signifying Practices. Sage Publications.

Hernández-Torrano, D., \& Ibrayeva, L. (2020). Creativity and education: A bibliometric mapping of the research literature (19752019). Thinking Skills and Creativity, 35(September 2019). https://doi.org/10.1016/j.tsc.2019.100625

Ho, W. C. (2014). Music education curriculum and social change: A study of popular music in secondary schools in Beijing, China. Music Education Research, 16(3), 267-289.

https://doi.org/10.1080/14613808.2014.91 0182

Holt, L., Bowlby, S., \& Lea, J. (2013). Emotions and the habitus: Young people with socio-emotional differences (re)producing social, emotional and cultural capital in family and leisure space-times. Emotion, Space and Society, 9(1), 33-41. https://doi.org/10.1016/j.emospa.2013.02. 002

Iryanti, V. E., Lestari, W., \& Bisri, M. H. (2021). Textual Study of Sandul Performance Candigaron Village Sumowono District Semarang Regency. SSRN Electronic Journal. https://doi.org/10.2139/ssrn.3800633

James, K., \& Sternberg, R. J. (2010). The Cambridge Handbook of Creativity. Cambridge University Press.

Johansson, K. (2012). Experts, entrepreneurs and competence nomads: The skills paradox in higher music education. Music Education Research, 14(1), 45-62. https://doi.org/10.1080/14613808.2012.65 7167

Kattsoff, L. O. (2004). Pengantar Filsafat (Soemargono-terj (Ed.)). Tiara Wacana Yogya.

Kearns, A. J. (2019). The ethical demand in teaching and learning. Teaching and Teacher Education, 86. https://doi.org/10.1016/j.tate.2019.07.004

Ki Hadjar Dewantara. (2004). Karya Ki Hadjar 
Rifky Fandanu ${ }^{1}$, Wahyu Lestari ${ }^{2}$, Suharto $^{3}$

Diversitas Pendidikan Multidimensional Dalam Pertunjukan Kentongan Bambu Laras

Banyumas Jawa Tengah

Dewantara Bagian I: Pendidikan. Majelis Luhur Persatuan Taman Siswa.

Koopman, C. (2005). Music education, performativity and aestheticization. Educational Philosophy and Theory, $37(1)$, $119-131$. https://doi.org/10.1111/j.14695812.2005.00102.x

Koops, L. H. (2017). The Enjoyment Cycle: A Phenomenology of Musical Enjoyment of 4- to 7-Year-Olds during Musical Play. Journal of Research in Music Education, 65(3), 360-380. https://doi.org/10.1177/002242941771692 1

Lestari, W., \& Barus, S. S. (2021). Budhe Centil Cross Gender Dance Hori Art \& Entertainment Yogyakarta as Breakthrough Forms of the Z Generation. SSRN Electronic Journal. https://doi.org/10.2139/ssrn.3800610

Lin, S.-F. (2019). Discovering Young Children's Musical Creativity in Their Everyday Life. In Y. Tsubonou, A.-G. Tan, \& M. Oie (Eds.), Creativity in Music Education (pp. 59-72). Springer.

Lo, Y. K. (2015). The Seven Worthies of the Bamboo Grove. In X. Liu (Ed.), Dao Companion to Daoist Philosophy (pp. 425-447). Springer Netherlands. https://doi.org/10.1007/978-90-481-29270_18

Lundström, H. (2018). Music Among Ethnic Minorities in Southeast Asia. In R. Bader (Ed.), Springer Handbook of Systematic Musicology (pp. 987-1004). Springer Berlin Heidelberg. https://doi.org/10.1007/978-3-662-550045_50

Lune, H., \& Berg, B. L. (2017). Qualitative Research Methods for the Social Sciences (Ninth edit). Pearson.

Mantie, R. (2013). A comparison of "popular music pedagogy" discourses a comparison of "popular music pedagogy" discourses. Journal of Research in Music Education, 61(3), 334-352. https://doi.org/10.1177/002242941349723 5

Mignonneau, L., \& Sommerer, C. (2005). Designing emotional, metaphoric, natural and intuitive interfaces for interactive art, edutainment and mobile communications. Computers and Graphics (Pergamon),
29(6),

$837-851$. https://doi.org/10.1016/j.cag.2005.09.001

Miles, M. B., Huberman, A. M., \& Saldana, J. (2018). Qualitative Data Analysis: A Methods Sourcebook (4th ed.). Sage Publications.

Mishra, J., Day, K., Littles, D., \& Vandewalker, E. (2011). A content analysis of introductory courses in music education at NASM-accredited colleges and universities. Bulletin of the Council for Research in Music Education, 190, 7-19.

Muzaffar, I., \& Otero-Pailos, J. (2015). Preservation and Globalization. Future Anterior: Journal of Historic Preservation, History, Theory, and Criticism, 9(1). https://doi.org/10.1353/fta.2012.0007

Noble, J., \& McAdams, S. (2020). Sound mass, auditory perception, and 'post-tone' music. Journal of New Music Research, 49(3),

231-251. https://doi.org/10.1080/09298215.2020.17 49673

Noland, C. (2009). Agency \& Embodiment: Performing Gestures/Producing Culture. Harvard University Press.

Nurseto, G., Lestari, W., \& Hartono. (2015). Pembelajaran Seni Tari: Aktif, Inovatif Dan Kreatif. Catharsis, 4(2), 115-122.

Patelli, P. (2017). A field is to play. Enacting mental images of the soundscape. Emotion, Space and Society, 25, 44-53. https://doi.org/10.1016/j.emospa.2016.11. 002

Pitts, S. E. (2017). What is music education for? Understanding and fostering routes into lifelong musical engagement. Music Education Research, 19(2), 160-168. https://doi.org/10.1080/14613808.2016.11 66196

Prier, K.-E. (1989). Ilmu Harmoni. Pusat Musik Liturgi.

Putriningtyas, I., Lestari, W., \& Hartono. (2015). Nilai Budi Pekerti Pada Ragam Gerak Tari Topeng Lanyapan Alus Kabupaten Tegal. Catharsis, 4(2), 92-98.

Rivers, T. M. (2016). Ten Essentials for Character Education. The Journal of General Education, 53(3), 247-260.

Rutter, M., \& Garmezy, N. (1983). Developmental Psychopathology. In Handbook Of Child Psychology (4th ed.). Wiley. 
Sampurno, M. B. T., Prabandari, Y. S., \& Marianto, M. D. (2020). Theoretical Exploration of Art Therapy and Education for Autistic Children. International Journal of Indonesian Education and Teaching (IJIET), 4(2). https://doi.org/10.24071/ijiet.2020.040209

Sampurno, T. (2015). Seni, Melukis, dan Anak Autis: Penanganan dan Pengembangan melalui Seni dan Cara Mengevaluasi Karya Anak Autis. Psikosain.

Sasongko, W. S. (2017). Kreativitas Musik pada Grup Kentongan Adiyasa di Kabupaten Banyumas. Seni Musik Unnes, 6(2), 66-80.

Shields, D. L. (2015). Character as the Aim of Education. The Phi Delta Kappan, 78(6), 428-439.

Shkedi, A. (2019). Introduction to Data Analysis in Qualitative Research. Springer International Publishing.

Soewarlan, S. (2019). Re-creating rural performing arts for tourism in Indonesia. Journal of Tourism and Cultural Change, 17(5), 577-593. https://doi.org/10.1080/14766825.2018.15 41993

Stevens, M. L. (2018). Culture and Education. Annals of the American Academy of Political and Social Science, 619(1), 97113. https://doi.org/10.1177/000271620832004 3

Tashakkori, A., \& Creswell, J. (2008). Mixed Methodology Across Disciplines. Journal Of Mixed Methods Research, 2(1), 1-5.

Thibeault, M. D. (2020). Dewey's Musical Allergy and the Philosophy of Music Education. Journal of Research in Music Education, 68(1), 31-52. https://doi.org/10.1177/002242941989679 2

Tuchman-Rosta, C. (2014). From Ritual Form to Tourist Attraction: Negotiating the Transformation of Classical Cambodian Dance in a Changing World. Asian Theatre Journal, 31(2), 524-544. https://doi.org/10.1353/atj.2014.0033

Van Manen, M. (1995). On the epistemology of reflective practice. Teachers and Teaching, 1(1), 35-50.

Weiss, S. (2010). Listening to an earlier Java: Aesthetics, gender, and the music of wayang in central Java. Listening to an Earlier Java: Aesthetics, Gender, and the
Music of Wayang in Central Java, 237, 1187.

https://doi.org/10.1163/9789004253698

Wiggins, T. (2015). Music, education, and sustainability. The World of Music, 4(1), $35-44$.

Willis, J. (2007). The neuroscience of joyful education. Educational Leadership, 64, 14.

Woody, R. H., Fraser, A., Nannen, B., \& Yukevich, P. (2019). Musical identities of older adults are not easily changed: an exploratory study. Music Education Research, 21(3), 315-330. https://doi.org/10.1080/14613808.2019.15 98346 